\title{
Added Diagnostic Value of Cerebrospinal Fluid Biomarkers for Differential Dementia Diagnosis in an Autopsy-Confirmed Cohort
}

\author{
Ellis Niemantsverdriet ${ }^{\mathrm{a}}$, Bart F.E. Feyen ${ }^{\mathrm{a}, \mathrm{c}}$, Nathalie Le Bastard ${ }^{\mathrm{a}, \mathrm{d}}$, Jean-Jacques Martin ${ }^{\mathrm{a}}$, \\ Johan Goeman $^{\mathrm{b}}$, Peter Paul De Deyn ${ }^{\mathrm{a}, \mathrm{b}}$, Maria Bjerke ${ }^{\mathrm{a}}$ and Sebastiaan Engelborghs ${ }^{\mathrm{a}, \mathrm{b}, *}$ \\ ${ }^{a}$ Reference Center for Biological Markers of Dementia (BIODEM), Laboratory of Neurochemistry and Behavior, \\ and Biobank, Institute Born-Bunge, University of Antwerp, Antwerp, Belgium \\ ${ }^{\mathrm{b}}$ Department of Neurology and Memory Clinic, Hospital Network Antwerp (ZNA) Middelheim and Hoge Beuken, \\ Antwerp, Belgium \\ ${ }^{\mathrm{c} C u r r e n t ~ a f f i l i a t i o n: ~ D e p a r t m e n t ~ o f ~ N e u r o s u r g e r y, ~ U n i v e r s i t y ~ H o s p i t a l ~ A n t w e r p, ~ E d e g e m, ~ B e l g i u m ~}$ \\ ${ }^{\mathrm{d}}$ Current affiliation: Fujirebio Europe, Ghent, Belgium
}

Handling Associate Editor: Patrizia Mecocci

Accepted 2 February 2018

\begin{abstract}
.
Background: Differential dementia diagnosis remains a challenge due to overlap of clinical profiles, which often results in diagnostic doubt.

Objective: Determine the added diagnostic value of cerebrospinal fluid (CSF) biomarkers for differential dementia diagnosis as compared to autopsy-confirmed diagnosis.

Methods: Seventy-one dementia patients with autopsy-confirmed diagnoses were included in this study. All neuropathological diagnoses were established according to standard neuropathological criteria and consisted of Alzheimer's disease (AD) or other dementias (NONAD). CSF levels of A $\beta_{1-42}$, T-tau, and P-tau 181 were determined and interpreted based on the IWG-2 and NIA-AA criteria, separately. A panel of three neurologists experienced with dementia made clinical consensus dementia diagnoses. Clinical and CSF biomarker diagnoses were compared to the autopsy-confirmed diagnoses.

Results: Forty-two patients (59\%) had autopsy-confirmed AD, whereas 29 patients (41\%) had autopsy-confirmed NONAD. Of the 24 patients with an ambiguous clinical dementia diagnosis, a correct diagnosis would have been established in $67 \%$ of the cases applying CSF biomarkers in the context of the IWG-2 or the NIA-AA criteria respectively.

Conclusion: AD CSF biomarkers have an added diagnostic value in differential dementia diagnosis and can help establishing a correct dementia diagnosis in case of ambiguous clinical dementia diagnoses.
\end{abstract}

Keywords: Ambiguous diagnosis, Alzheimer's disease, biomarkers, cerebrospinal fluid, dementia, differential dementia diagnosis, neuropathology

\section{INTRODUCTION}

Alzheimer's disease (AD) and other types of dementia (non-AD) overlap in clinical profiles, and

\footnotetext{
${ }^{*}$ Correspondence to: Prof. Dr. Sebastiaan Engelborghs, MD, UAntwerp, Universiteitsplein 1, BE-2610 Antwerp, Belgium. Tel.: +32 3265 2394; Fax: +32 3265 2669; E-mail: Sebastiaan.Engelborghs@uantwerpen.be.
}

therefore the differential dementia diagnosis remains challenging and diagnostic errors continue to appear. These errors generally concern uncertainties in early diagnosis, or could involve one of the other primary dementias, co-pathologies, or pathologies including a vascular component. Moreover, misdiagnoses of patients with vascular lesions confirmed by structural brain imaging as possible or probable vascular 
dementia (VaD) often occur [1]. Diagnostic accuracy should improve by minimizing errors in clinical diagnosis, and a possible approach is the use of cerebrospinal fluid (CSF) biomarkers. The standard AD CSF biomarker panel that consists of amyloid- $\beta$ of 42 amino acids $\left(A \beta_{1-42}\right)$, total tau protein ( $\left.\mathrm{T}-\mathrm{tau}\right)$, and hyperphosphorylated tau (P-tau), increases the diagnostic accuracy for AD [2], also in its prodromal phase [3], and is used in daily clinical practice [4]. However for differential dementia diagnosis, the use of this AD CSF biomarker panel is limited due to an overlap in CSF levels of $A \beta_{1-42}$ and T-tau between $\mathrm{AD}$ and non- $\mathrm{AD}$ dementias, especially in case of $\mathrm{AD}$ co-pathology in the brain of non-AD dementias, like dementia with Lewy bodies (DLB) $[2,5] . \mathrm{P}-\operatorname{tau}_{181}$ is an essential component of the AD CSF biomarker panel and has the highest diagnostic power to discriminate between $\mathrm{AD}$ and non- $\mathrm{AD}$ dementias [6]. Although the added diagnostic value of the AD CSF biomarker panel was demonstrated in case of ambiguous clinical dementia diagnoses (when a clinical diagnostic work-up was not able to discriminate between $\mathrm{AD}$ and a non-AD dementia) [7], the added diagnostic value when applying the IWG-2 [8] and NIA-AA criteria [9] has not been taken into account for differential dementia diagnosis. We aimed to investigate a cohort of clinically assessed patients who also underwent lumbar puncture (LP) and were followed-up by autopsy. This enables us to compare the clinical (non-biomarker-based) and CSF biomarker diagnoses (IWG-2 or NIA-AA criteria based diagnoses), with the autopsy-confirmed neuropathological diagnoses as the reference.

\section{MATERIALS AND METHODS}

\section{Study population}

The study population consisted of 71 demented patients with autopsy-confirmed dementia diagnoses. Patients were recruited through the Memory Clinic of Hospital Network Antwerp (ZNA) Middelheim and Hoge Beuken $(n=64)$ and through centers referring to the Biobank of the Institute Born-Bunge $(n=7)$ [1]. Based on the information collected during the clinical diagnostic work-up at enrollment in the study, a panel of three neurologists experienced with neurodegenerative diseases and dementia (JG, PPDD, SE) made a consensus clinical dementia diagnosis (not biomarker-based). The panel was blinded for the initial clinical and neuropathological diagnoses. The presented clinical information (by BF) consisted of age at inclusion/death, gender, history of and concomitant illnesses, familial and social history, onset and history of presented complaint(s), medication, physical and clinical neurological examination, a complete neuropsychological examination including (among others) Mini-Mental State Examination (MMSE) scores [1], brain magnetic resonance imaging (MRI), and/or computed tomography (CT) scan.

This study was approved by the ethics committee of UAntwerp, Antwerp, Belgium (UA A07-24). All included subjects and/or caregiver signed an informed consent.

\section{Clinical diagnostic criteria}

The clinical panel established consensus diagnoses based on standard clinical diagnostic criteria, allowing to label each clinical diagnosis as probable or possible depending on the likelihood of it being the cause of dementia. The diagnostic procedure did not include CSF biomarkers.

The diagnosis of possible/probable AD was made according to the NINCDS-ADRDA criteria [10]. In case patients fulfilled the criteria of probable $A D$ and, in addition, displayed cerebrovascular disease (CVD) on brain CT and/or MRI that, however, did not meet the criteria of relevant CVD according to NINDS-AIREN criteria of VaD [11], patients were diagnosed with a combination of $\mathrm{AD}$ and CVD. For the diagnosis of $\mathrm{VaD}$ the NINDS-AIREN criteria were applied [11]. Criteria described by Neary [12] were applied for the diagnosis of probable frontotemporal dementia (FTD). DLB was diagnosed according to the clinical diagnostic criteria of McKeith [13]. Parkinson's disease dementia (PDD) was diagnosed when patients with idiopathic Parkinson's disease (PD) developed dementia following a dementia-free interval of at least two years. Idiopathic PD was diagnosed based on the presence of at least two out of four motor manifestations that characterize the disease and an insidious onset [14]. Diagnosing CreutzfeldtJakob disease (CJD) was established according to the diagnostic criteria of Weber [15].

\section{Neuropathological criteria}

All pathological diagnoses were made using standard neuropathological criteria by the same neuropathologist (JJM). The neuropathologist was blinded to the consensus diagnoses, but had access 
to all neuroimaging data. $\mathrm{AD}, \mathrm{VaD}$, and $\mathrm{DLB}$ were neuropathologically diagnosed based on the criteria of Montine [16]. For the diagnosis of FTD the neuropathological criteria of Cairns [17] and Mackenzie $[18,19]$ were applied. CJD was diagnosed according to Markesbery [20]. Neuropathology was executed on the right hemisphere of the brain.

\section{CSF sampling and storage}

CSF was obtained by LP at the L3/L4 or L4/L5 interspace. CSF samples were immediately frozen in liquid nitrogen and stored at $-75^{\circ} \mathrm{C}$ until analysis, as previous described [4]. The samples were collected at the Memory Clinic of ZNA Middelheim and other centers referring to the Biobank of the Institute BornBunge according to a standard protocol [4]. In here, non-blood contaminated samples did not undergo centrifugation, whereas in case of a hemorrhagic LP detected by macroscopic inspection, CSF was centrifuged for $10 \mathrm{~min}$ at $3000 \mathrm{rpm}$ within 4 hours after LP. The supernatant was thereafter transferred to an unused polypropylene vial.

\section{CSF analysis and interpretation}

CSF analysis was performed at the BIODEM lab. The laboratory technician was blinded for the clinical and pathological diagnoses when performing and interpreting the tests. CSF levels of $\mathrm{A} \beta_{1-42}$, T-tau, and P-tau ${ }_{181}$ were determined with commercially available singe-analyte ELISA kits INNOTEST $^{\circledR}, \beta-$ AMYLOID $_{(1-42)}$, INNOTEST $^{\circledR}$ hTAU-Ag, and INNOTEST ${ }^{\circledR}$ PHOSPHOTAU $_{(181 P)}$, Fujirebio Europe, Ghent, Belgium). All samples were run in duplicate. The concentration ranges of the test kits are described in the package inserts $\left(A \beta_{1-42}\right.$ : 125-2000 pg/mL, T-tau: 75-1200 pg/mL, P-tau 181 : $15.6-500 \mathrm{pg} / \mathrm{mL}$ ). If CSF concentrations were out of range, the concentrations were set to the upper/lower limit of the kit inserts. For the statistical analyses all patients were included as the out-of-range concentrations did not affect the CSF biomarker profiles.

The three CSF biomarkers results were interpreted based on in-house validated cut-off values (in autopsy-confirmed $\mathrm{AD}$ versus cognitively healthy elderly; $\mathrm{A} \beta_{1-42}<638.50 \mathrm{pg} / \mathrm{mL}$, T-tau $>296.50 \mathrm{pg} / \mathrm{mL}, \mathrm{P}_{\mathrm{tau}} 181>56.50 \mathrm{pg} / \mathrm{mL}$ ) [21].

CSF biomarkers were analyzed by applying the IWG-2 criteria [8] for AD and the NIA-AA criteria [9] separately (Supplementary Table 1). CSF A $\beta_{1-42}$ is indicative of $\mathrm{AD}$ if the concentration is below the cut-off and CSF tau biomarkers if the concentrations are above the cut-off. By applying the IWG-2 criteria a CSF biomarker profile was considered to be suggestive for $A D$ if $C S F A \beta_{1-42}$, in combination with T-tau and/or P-tau 181 values were altered. In all other cases, the CSF biomarker profile was not suggestive for $\mathrm{AD}$. In addition, the NIA-AA criteria were applied, with a high likelihood of AD if both amyloid and neuronal injury markers were altered, whereas the low likelihood was if both markers were unaltered. Intermediate likelihood was if only one of both was altered.

\section{Categorization of diagnoses}

Subjects with neuropathological diagnoses of AD or $\mathrm{AD}$ with $\mathrm{CVD}$ were pooled in the $\mathrm{AD}$ group whereas we refer to non-AD in case of other dementias. The latter, was subdivided into patients without a co-pathology (non-AD) and patients with a primary non-AD pathology and AD co-pathology. Subjects with a single clinical diagnosis were categorized as "unique" (e.g., probable AD). In case of doubt between two clinical diagnoses following the clinical diagnostic work-up, subjects were categorized as "ambiguous" (there was doubt between two clinical diagnoses belonging to both $\mathrm{AD}$ and non-AD categories, e.g., probable $\mathrm{AD}$ /possible FTD).

\section{Statistical analyses}

Statistical analyses were performed using IBM SPSS Statistics 23 and GraphPad Prism 6. To describe and analyze our entire cohort, categorical variables were analyzed with a Chi-Square test, and percentages, sensitivity, specificity, and positive/negative predictive values were reported. Independent pairwise comparisons were performed with Mann Whitney U test, and demographic variables were reported as mean values with SD and biomarkers variables by median with interquartile range (IQR). For all analyses, $p$-values below 0.05 were considered significant.

\section{RESULTS}

\section{Population (Table 1)}

In this cohort $(n=71)$, there was no significant difference in the proportion of gender between the three patient groups. Forty-two patients in the 
Table 1

Description of the population

\begin{tabular}{|c|c|c|c|c|}
\hline & \multicolumn{3}{|c|}{ Pathological diagnosis } & \multirow[t]{2}{*}{$p$-value } \\
\hline & $\mathrm{AD}(n=42)$ & non-AD $(n=22)$ & $\begin{array}{c}\text { Primary non-AD with } \\
\text { AD co-pathology }(n=7)\end{array}$ & \\
\hline Gender ( $\%$ male/female) & $52 / 48$ & $59 / 41$ & $43 / 57$ & 0.735 \\
\hline Age at inclusion (y) & $80.1[ \pm 9.0]$ & $69.5[ \pm 12.1]$ & $75.9[ \pm 8.5]$ & $0.001^{\wedge}$ \\
\hline Age at death (y) & $82.0[ \pm 8.3]$ & $70.8[ \pm 11.8]$ & $76.9[ \pm 8.7]$ & $0.001^{\wedge}$ \\
\hline MMSE (score out of 30) (n) & $13.5[ \pm 6.3](36)$ & $16.0[ \pm 7.2](16)$ & $16.0[ \pm 6.8](7)$ & NS \\
\hline Interval inclusion - autopsy (y) & $1.7[ \pm 2.6]$ & $1.4[ \pm 1.7]$ & $0.9[ \pm 1.3]$ & NS \\
\hline $\begin{array}{l}\text { Interval last clinical evaluation - } \\
\text { autopsy (y) }\end{array}$ & $0.8[ \pm 1.7]$ & $0.6[ \pm 1.0]$ & $0.4[ \pm 0.9]$ & NS \\
\hline $\mathrm{CSF} A \beta_{1-42}(\mathrm{pg} / \mathrm{mL})$ & 394.5 [280.3-506.3] & $463.3[378.0-573.8]$ & $450.1[438.0-537.0]$ & NS \\
\hline CSF T-tau (pg/mL) & 723.7 [358.0-1200.08] & 544.7 [211.8-976.0] & 645.4 [375.0-1200.0] & NS \\
\hline CSF P-tau $181(\mathrm{pg} / \mathrm{mL})$ & $103.3[58.3-137.3]$ & $73.4[25.4-69.6]$ & $67.2[46.3-82.5](7)$ & $0.001^{\wedge, \$}$ \\
\hline
\end{tabular}

Data are presented as mean [ $\pm \mathrm{SD}$ ] values, percentage $(\%)$, or number $(\mathrm{n})$. CSF biomarker data are presented as median values [IQR].

${ }^{\wedge}$ Significantly different between $\mathrm{AD}$ and non-AD patient group. ${ }^{\$}$ Significantly different between $\mathrm{AD}$ and non-AD with AD co-pathology. $\mathrm{AD}$, Alzheimer's disease; $\mathrm{A} \beta_{1-42}$, amyloid- $\beta$ of 42 amino acids; CSF, cerebrospinal fluid; IQR, interquartile range; MMSE, Mini-Mental State Examination; non-AD, other type of dementia (than Alzheimer's disease); NS, not significant; P-tau 181 , phosphorylated tau at Threonine 181 ; SD, standard deviation; T-tau, total tau protein.

population (59\%) had neuropathologically confirmed $\mathrm{AD}$, whereas $29(41 \%)$ patients showed non-AD neuropathology findings. Seven out of the 29 non-AD patients (24\%) had primary non-AD neuropathology with an AD co-pathology (DLB $n=4, \mathrm{VaD} n=1$, FTD $n=1$, CJD $n=1$ ). The non-AD group (FTD $n=8$, DLB $n=6, \mathrm{VaD} n=5, \mathrm{CJD} n=3$ ) was significantly younger at inclusion and at death than the AD group. MMSE scores were not significantly different comparing the three groups. The interval between inclusion (time of LP) and autopsy was in most cases short $(1.5 \pm 2.3$ years, of which $70.4 \%$ of the patients died within one year following inclusion), likewise the interval between last clinical evaluation and autopsy ( $0.7 \pm 1.5$ years). No significant differences were observed comparing intervals between inclusion/last clinical evaluation and autopsy between $\mathrm{AD}$ and non-AD groups. CSF P-tau 181 concentrations were significantly different, comparing the $\mathrm{AD}$ and non-AD patient group $(p=0.001)$, whereas no significant differences were detected for CSF $A \beta_{1-42}$ and T-tau. No significant differences were observed between $\mathrm{AD}$ or non- $\mathrm{AD}$ and the non- $\mathrm{AD}$ with $\mathrm{AD}$ co-pathology. The CSF $A \beta_{1-42}$ concentration was lower, whereas T-tau and P-tau 181 concentrations were higher in the $\mathrm{AD}$ group as compared to the non-AD group. The non-AD with AD copathology group had intermediate CSF biomarker concentrations.

\section{Diagnostic value of CSF biomarkers (Table 2)}

By comparing the clinical consensus and CSF biomarker diagnoses in subjects with unique clinical diagnoses ( $n=47$, Tables 2a-b and 3, Supplementary Table 2), the diagnostic accuracy of CSF biomarker diagnoses (based on IWG-2 criteria or NIA-AA criteria) was not significantly different from the clinical diagnostic accuracy ( $p=0.162$ and $p=0.473$, respectively) using the autopsy-confirmed diagnosis as a reference. Therefore, no added value of the CSF biomarkers was detected as compared to the clinical diagnosis in patients with a unique clinical diagnosis. Nevertheless, $60 \%$ of the clinically incorrect diagnosed patients would have been correctly diagnosed with CSF biomarkers following the IWG-2 criteria, and $75 \%$ following the NIA-AA criteria. Those patients had a biomarker profile suggestive for $\mathrm{AD}$ and were neuropathologically diagnosed as $\mathrm{AD}$ $(n=5)$ or DLB with AD co-pathology $(n=1)$.

Four patients had incorrect CSF biomarker diagnoses (both IWG-2 and NIA-AA criteria) with correct clinical diagnosis and were neuropathologically confirmed as CJD $(n=2)$, FTD $(n=1)$, or DLB $(n=1)$. In addition, three subjects were incorrect CSF biomarker-based diagnosed as non-AD following the IWG-2 criteria with correct clinical diagnoses and neuropathologically confirmed as AD (abnormal CSF $A \beta_{1-42}$ with normal tau values).

An incorrect diagnosis for both the clinical and CSF-biomarker diagnosis (both IWG-2 and NIAAA criteria) was detected in two subjects, namely neuropathologically diagnosed as CJD or DLB. In addition, two subjects were incorrect CSF biomarkerbased diagnosed as non-AD following the IWG-2 criteria incorrect clinical diagnoses and neuropathologically confirmed as AD (abnormal CSF $\mathrm{A} \beta_{1-42}$ with normal tau values). 
Table 2

\begin{tabular}{|c|c|c|c|}
\hline \multicolumn{4}{|c|}{$\begin{array}{l}\text { a. Clinical diagnosis versus CSF biomarker-based diagnos } \\
\text { autopsy-confirmed diagnosis as a reference }(p=0.162)\end{array}$} \\
\hline & $\begin{array}{c}\text { Biomarker diagnosis } \\
\text { Correct }\end{array}$ & $\begin{array}{l}\text { Biomarker diagnosis } \\
\text { Incorrect }\end{array}$ & Total \\
\hline Clinical diagnosis Correct & 30 & 7 & 37 \\
\hline osis Incorrect & 6 & 4 & 10 \\
\hline Total & 36 & 11 & 47 \\
\hline \multicolumn{4}{|c|}{$\begin{array}{l}\text { b. Clinical diagnosis versus CSF biomarker-based diagnosis according to the NIA-AA criteria, using the } \\
\text { autopsy-confirmed diagnosis as a reference }(p=0.473)\end{array}$} \\
\hline & $\begin{array}{l}\text { Biomarker diagnosis } \\
\text { Correct }\end{array}$ & $\begin{array}{l}\text { Biomarker diagnosis } \\
\text { Incorrect }\end{array}$ & Total \\
\hline Correct & 24 & 4 & 28 \\
\hline Clinical diagnosis Incorrect & 6 & 2 & 8 \\
\hline Total & 30 & 6 & 36 \\
\hline \multicolumn{4}{|c|}{$\begin{array}{l}\text { In total, } 24 \text { subjects had an ambiguous clinical diagnosis and were excluded from this analysis. The other } 47 \text { individ- } \\
\text { uals were subdivided into concordance/discordance between the clinical diagnoses and CSF biomarker diagnosis, } \\
\text { both for the IWG- } 2 \text { criteria (a) and NIA-AA criteria (b), compared to neuropathological diagnosis. Eleven subjects } \\
\text { with an intermediate clinical diagnosis based on the NIA-AA criteria were not included in Table } 2 \mathrm{~b} \text { as we could not } \\
\text { decide if they were correctly or incorrectly CSF biomarker-based diagnosed compared to the neuropathological } \\
\text { diagnosis. Table } 2 \mathrm{a}(n=47) \text {, the sensitivity, specificity, diagnostic accuracy, and positive/negative predicted values } \\
\text { were calculated for both the clinical and CSF biomarker diagnosis compared to the neuropathological diagnosis } \\
\text { (respectively, clinically } 78 \%, 80 \%, 79 \% \text {, and } 89 \% / 63 \% \text {; and for CSF biomarker-based diagnosis } 84 \%, 40 \%, 70 \% \text {, } \\
\text { and } 75 \% / 55 \% \text { ). Table } 2 \mathrm{~b}(n=36) \text {, the sensitivity, specificity, diagnostic accuracy, and positive/negative predicted } \\
\text { values were calculated for both the clinical and CSF biomarker diagnosis compared to the neuropathological diag- } \\
\text { nosis (respectively, clinically } 82 \%, 67 \% \text {, } 78 \% \text {, and } 88 \% / 55 \% \text {; and for CSF biomarker-based diagnosis } 100 \%, 67 \% \text {, } \\
92 \% \text {, and } 90 \% / 100 \%) \text {. CSF, cerebrospinal fluid; IWG-2, International Working Group; NIA-AA, National Institute } \\
\text { on Aging/Alzheimer's Association. }\end{array}$} \\
\hline
\end{tabular}

\section{Diagnoses of ambiguous clinical cases (Table 3)}

In 24 out of the 71 subjects an ambiguous clinical diagnosis was detected, i.e., where the panel was not able to categorize the patient in the $\mathrm{AD}$ group or the non-AD patient group. The outcome was either a success (when diagnostic categories of pathology and of CSF biomarkers according to the IWG-2 or NIA-AA criteria for individual patients matched) or a failure (when diagnostic categories did not match).

A correct CSF biomarker diagnosis based on the IWG- 2 criteria was established in 16 ( $\mathrm{AD} n=9$, non$\mathrm{AD} n=3$, or non-AD with AD co-pathology (DLB $n=2, \mathrm{VaD} n=1, \mathrm{FTD} n=1)$ ) out of $24(67 \%)$ patients as compared to the autopsy-confirmed diagnosis. Of the eight patients who were incorrectly diagnosed based on CSF biomarkers, the confirmed diagnosis of three patients was not one of the ambiguous clinical diagnosed probabilities (e.g., the clinical differential diagnosis consisted of $\mathrm{AD}$ versus $\mathrm{VaD}$, whereas the autopsy-confirmed diagnosis was FTD). The other five patients were neuropathologically confirmed as one of the ambiguous clinical diagnosed probabilities (e.g., the clinical differential diagnosis consisted of $\mathrm{AD}$ versus $\mathrm{DLB}$, and the autopsy-confirmed diagnosis was DLB).
Using the CSF biomarkers following the NIAAA criteria, a correct diagnosis was established in $14 / 21(67 \%)$ individuals as compared to the autopsyconfirmed diagnoses. One patient was diagnosed with the low likelihood of AD and CSF biomarkers in the context of the IWG-2 criteria resulted in a 'non AD' CSF biomarker profile. This patient was neuropathologically diagnosed with non-AD (FTD). Thirteen patients had a high likelihood of AD and were neuropathologically confirmed as $\mathrm{AD}(n=9)$ or non-AD with $\mathrm{AD}$ co-pathology $(n=4)$. The other seven patients were incorrectly diagnosed using the CSF biomarkers in the context of the NIA-AA criteria, all with a high likelihood of $\mathrm{AD}$, and were neuropathologically confirmed as $\operatorname{VaD}(n=4)$, FTD $(n=2)$, or DLB $(n=1)$. Three patients who had an intermediate likelihood of AD based on the NIA-AA criteria were not included in this analysis.

\section{Intermediate NIA-AA CSF biomarker-based diagnosis}

In total 14 subjects had an intermediate NIA-AA diagnosis (Table 3 ) and were not included in the clinical versus CSF biomarker-based diagnosis comparison (Table 2b) as we could not decide if they were 
Table 3

Patients with ambiguous clinical diagnoses as compared to CSF biomarker-based diagnoses using the IWG-2 criteria

\begin{tabular}{lcccc}
\hline Clinical diagnosis (n) & $\begin{array}{c}\text { Suggestive } \\
\text { for AD }\end{array}$ & $\begin{array}{c}\text { Correct biomarker } \\
\text { diagnosis }(\%)\end{array}$ & $\begin{array}{c}\text { Not suggestive } \\
\text { for AD }\end{array}$ & $\begin{array}{c}\text { Correct biomarker } \\
\text { diagnosis }(\%)\end{array}$ \\
\hline Probable AD/Probable non-AD (5) & 4 & 75 & 1 & 100 \\
Probable AD/Possible non-AD (15) & 13 & 62 & 2 & 50 \\
Probable non-AD/Possible AD (3) & 2 & 50 & 1 & 100 \\
Possible AD/Possible non-AD (1) & 1 & 100 & 0 & 0 \\
\hline
\end{tabular}

Data are number of patients (n) and correct relative number of diagnoses (\%). The category 'suggestive for AD' consists of patients with an AD CSF biomarker profile according to the IWG-2 criteria, whereas 'not suggestive for AD' were patients with CSF biomarkers not suggestive for AD according to the IWG-2 criteria. A correct diagnosis was based if the diagnostic categories of pathology and of CSF biomarkers according to the IWG-2 for individual patients matched, for instance if definite $\mathrm{AD}$ and cases with $\mathrm{AD}$ co-pathology had a positive biomarker profile. The sensitivity, specificity, diagnostic accuracy, and positive/negative predicted values were calculated for the CSF biomarker diagnoses based on the IWG-2 criteria compared to the neuropathological diagnosis (respectively, 90\%, 50\%, 67\%, and 56\%/88\%). AD, Alzheimer's disease; CSF, cerebrospinal fluid; IWG-2, International Working Group; NIA-AA, National Institute on Aging/Alzheimer's Association; non-AD, other type of dementia (than Alzheimer's disease).

correctly or incorrectly diagnosed according to the NIA-AA criteria in comparison to neuropathology as the reference.

In total six patients were neuropathologically confirmed as AD with incorrect CSF biomarker diagnosis based on the IWG- 2 criteria (abnormal CSF A $\beta_{1-42}$ with normal tau values, $n=5$; or normal $\mathrm{A} \beta_{1-42}$ with abnormal T-Tau values, $n=1$ ). The other eight patients with an intermediate likelihood based on the NIA-AA criteria (abnormal $A \beta_{1-42}$ with normal tau values, $n=6$ (FTD, $n=3$; DLB, $n=3$ ); or normal $\mathrm{A} \beta_{1-42}$ with abnormal tau values, $n=2$ (VaD and FTD)) were correctly diagnosed with the CSF biomarkers based on the IWG-2 criteria, and were neuropathologically diagnosed as FTD, DLB, or $\mathrm{VaD}$.

\section{DISCUSSION}

This study investigated whether CSF biomarkers levels could help the physician in differential dementia diagnoses using a cohort of 71 autopsy-confirmed patients, whereof 24 patients had an ambiguous clinical diagnosis. This study showed that by applying CSF biomarkers using the IWG-2 or NIA-AA criteria in patients with an ambiguous clinical diagnosis a correct diagnosis would have been established in $67 \%$ of patients using autopsy-confirmed dementia diagnosis as the reference. Moreover, IWG-2 and NIA-AA criteria performed equally well. We thus confirm that CSF biomarkers have an added diagnostic value in cases with ambiguous clinical diagnoses [7]. Therefore, biomarkers should be included in the diagnostic work-up in case of doubt between $\mathrm{AD}$ versus nonAD. CSF biomarkers contribute to a high accuracy for identifying $\mathrm{AD}$, also in prodromal AD [22-25], but several other brain diseases can lead to pathological values of these AD CSF biomarkers, which was also observed in this study. For instance, an increase in T-tau is also detected in disorders with extensive and/or rapid neuronal degeneration, such as CJD [26]. Moreover, both $\mathrm{A} \beta_{1-42}$ and T-tau are detected at intermediate levels in non-AD patients, in between normal control and abnormal AD values [2, 27-29], especially in DLB but also in FTD, VaD, and CJD. In order to improve the discriminatory power for the differential diagnosis of dementia, additional markers, more specific to the non-AD dementia can be valuable.

Even though, no added diagnostic value of CSF biomarkers was detected in case of unique clinical diagnosis, a correct CSF biomarker-based diagnosis following the IWG-2 or NIA-AA criteria with incorrect clinical diagnosis would have been established in $60 \%$ and $75 \%$ of the cases, respectively. When CSF biomarkers showed incorrect diagnosis compared to correct clinical diagnosis, the CSF biomarkers were in concordance with the neuropathology. Of those patients, three were neuropathologically confirmed with $\mathrm{AD}$ and had abnormal CSF $A \beta_{1-42}$ concentrations, nevertheless the CSF tau concentrations were normal and neuropathologically neurofibrillary tangles were found. The neuronal loss may not have been severe enough for tau to be released into the interstitial fluid, resulting in normal CSF tau values. In addition, four patients were neuropathologically diagnosed with non-AD (CJD; $n=2$, FTD; $n=1$, and DLB; $n=1)$ and all had abnormal CSF A $\beta_{1-42}$ values and amyloid plaques were found at autopsy, thus the biomarker was in concordance with the pathology. Nevertheless, the CJD patients had very high $\mathrm{T}$-tau values (abnormal), indicating a severe neuronal 
loss, typical of CJD, which is in line with the current literature [30, 31]. The FTD and DLB patients also had abnormal T-tau values and neuronal loss was neuropathologically confirmed.

Additionally, when patients had an intermediate likelihood CSF biomarker-based diagnosis of $\mathrm{AD}$ (according to the NIA-AA criteria), the IWG2 criteria could correctly diagnose eight of the 14 individuals in this study. The other six individuals with an intermediate likelihood CSF biomarkerbased diagnosis of AD (according to the NIA-AA criteria) had an incorrect CSF biomarker-based diagnosis (according to the IWG-2 criteria: abnormal $\mathrm{A} \beta_{1-42}$ and normal tau values). For those six patients the CSF biomarkers actually correctly reflected the pathology. This agreement was also found in case patients had both incorrect clinical and incorrect CSF biomarker-based diagnosis $(n=4)$. A possible solution to correct for the discordancy between CSF and clinical diagnosis could be the introduction of the CSF $A \beta_{1-42} / A \beta_{1-40}$ ratio [32]. These findings further underbuilt the recently published consensus recommendations that stress that AD CSF biomarkers should be applied as an add-on to the clinical evaluation in selected clinical indications [33, 34].

A limitation of this study might be the rather low cut-offs compared to other studies. However, our lab participates in the Alzheimer's Association external quality control program (AA QC) for CSF. Within this program our longitudinal samples were always lower in comparison to mean of all participating laboratories. Since we switched to kits with ready-to-use calibrators our longitudinal samples are in agreement with the mean of the other participating labs. Nevertheless, the individuals in this cohort were analyzed before the transition to ready-to-use calibrator kits. In addition, the in-house established cut-offs (based on autopsy-confirmed dementia subjects and cognitively healthy elderly) were also calculated before this transition, and therefore, we could rely on the applied cut-offs.

In conclusion, these findings show that the ADCSF biomarkers have an added diagnostic value in differential dementia diagnosis and can help establishing a correct dementia diagnosis in case of ambiguous clinical dementia diagnoses.

\section{ACKNOWLEDGMENTS}

The authors acknowledge the administrative assistance and the clinical staff of the Department of
Neurology and Memory Clinic of Hospital Network Antwerp (ZNA), Middelheim and Hoge Beuken, Antwerp, Belgium.

This work was funded in part by the University of Antwerp Research Fund; Institute Born-Bunge; Flanders Impulse Program on Networks for Dementia Research (VIND); Flanders Innovation \& Entrepreneurship (VLAIO); Research Foundation Flanders; EU/EFPIA Innovative Medicines Initiative Joint Undertaking (EMIF grant $\mathrm{n}^{\circ}$ 115372).

Authors' disclosures available online (https:// www.j-alz.com/manuscript-disclosures/17-0927r1).

\section{SUPPLEMENTARY MATERIAL}

The supplementary material is available in the electronic version of this article: http://dx.doi.org/ 10.3233/JAD-170927.

\section{REFERENCES}

[1] Niemantsverdriet E, Feyen BF, Le Bastard N, Martin JJ, Goeman J, De Deyn PP, Engelborghs S (2015) Overdiagnosing vascular dementia using structural brain imaging for dementia work-up. J Alzheimers Dis 45, 1039-1043.

[2] Engelborghs S, De Vreese K, Van de Casteele T, Vanderstichele H, Van Everbroeck B, Cras P, Martin JJ, Vanmechelen E, De Deyn PP (2008) Diagnostic performance of a CSF-biomarker panel in autopsy-confirmed dementia. Neurobiol Aging 29, 1143-1159.

[3] Hansson O, Zetterberg H, Buchhave P, Londos E, Blennow K, Minthon L (2006) Association between CSF biomarkers and incipient Alzheimer's disease in patients with mild cognitive impairment: A follow-up study. Lancet Neurol 5, 228-234.

[4] Somers C, Struyfs H, Goossens J, Niemantsverdriet E, Luyckx J, De Roeck N, De Roeck E, De Vil B, Cras P, Martin JJ, De Deyn PP, Bjerke M, Engelborghs S (2016) A decade of cerebrospinal fluid biomarkers for Alzheimer's disease in Belgium. J Alzheimers Dis 54, 383-395.

[5] Slaets S, Le Bastard N, Theuns J, Sleegers K, Verstraeten A, De Leenheir E, Luyckx J, Martin JJ, Van Broeckhoven C, Engelborghs S (2013) Amyloid pathology influences abeta1-42 cerebrospinal fluid levels in dementia with lewy bodies. J Alzheimers Dis 35, 137-146.

[6] Struyfs H, Niemantsverdriet E, Goossens J, Fransen E, Martin JJ, De Deyn PP, Engelborghs S (2015) Cerebrospinal fluid P-Tau181P: Biomarker for improved differential dementia diagnosis. Front Neurol 6, 138

[7] Le Bastard N, Martin JJ, Vanmechelen E, Vanderstichele H, De Deyn PP, Engelborghs S (2010) Added diagnostic value of CSF biomarkers in differential dementia diagnosis. Neurobiol Aging 31, 1867-1876.

[8] Dubois B, Feldman HH, Jacova C, Hampel H, Molinuevo JL, Blennow K, DeKosky ST, Gauthier S, Selkoe D, Bateman R, Cappa S, Crutch S, Engelborghs S, Frisoni GB, Fox NC, Galasko D, Habert MO, Jicha GA, Nordberg A, Pasquier F, Rabinovici G, Robert P, Rowe C, Salloway S, Sarazin M, Epelbaum S, de Souza LC, Vellas B, Visser PJ, 
Schneider L, Stern Y, Scheltens P, Cummings JL (2014) Advancing research diagnostic criteria for Alzheimer's disease: The IWG-2 criteria. Lancet Neurol 13, 614-629.

[9] McKhann GM, Knopman DS, Chertkow H, Hyman BT, Jack Jr CR, Kawas CH, Klunk WE, Koroshetz WJ, Manly JJ, Mayeux R, Mohs RC, Morris JC, Rossor MN, Scheltens P, Carrillo MC, Thies B, Weintraub S, Phelps $\mathrm{CH}$ (2011) The diagnosis of dementia due to Alzheimer's disease: Recommendations from the National Institute on Aging-Alzheimer's Association workgroups on diagnostic guidelines for Alzheimer's disease. Alzheimers Dement 7, 263-269.

[10] McKhann G, Drachman D, Folstein M, Katzman R, Price D, Stadlan EM (1984) Clinical diagnosis of Alzheimer's disease: Report of the NINCDS-ADRDA Work Group under the auspices of Department of Health and Human Services Task Force on Alzheimer's Disease. Neurology 34, 939-944.

[11] Roman GC, Tatemichi TK, Erkinjuntti T, Cummings JL, Masdeu JC, Garcia JH, Amaducci L, Orgogozo JM, Brun A, Hofman A, et al. (1993) Vascular dementia: Diagnostic criteria for research studies. Report of the NINDS-AIREN International Workshop. Neurology 43, 250-260.

[12] Neary D, Snowden JS, Gustafson L, Passant U, Stuss D, Black S, Freedman M, Kertesz A, Robert PH, Albert M, Boone K, Miller BL, Cummings J, Benson DF (1998) Frontotemporal lobar degeneration: A consensus on clinical diagnostic criteria. Neurology 51, 1546-1554.

[13] McKeith IG, Dickson DW, Lowe J, Emre M, O'Brien JT, Feldman H, Cummings J, Duda JE, Lippa C, Perry EK, Aarsland D, Arai H, Ballard CG, Boeve B, Burn DJ, Costa D, Del Ser T, Dubois B, Galasko D, Gauthier S, Goetz CG, Gomez-Tortosa E, Halliday G, Hansen LA, Hardy J, Iwatsubo T, Kalaria RN, Kaufer D, Kenny RA, Korczyn A, Kosaka K, Lee VM, Lees A, Litvan I, Londos E, Lopez OL, Minoshima S, Mizuno Y, Molina JA, Mukaetova-Ladinska EB, Pasquier F, Perry RH, Schulz JB, Trojanowski JQ, Yamada M, Consortium on DLB (2005) Diagnosis and management of dementia with Lewy bodies: Third report of the DLB Consortium. Neurology 65, 1863-1872.

[14] Hoehn MM, Yahr MD (1967) Parkinsonism: Onset, progression and mortality. Neurology 17, 427-442.

[15] Weber $\mathrm{T}$ (2000) Clinical and laboratory diagnosis of Creutzfeldt-Jakob disease. Clin Neuropathol 19, 249-250.

[16] Montine TJ, Phelps CH, Beach TG, Bigio EH, Cairns NJ, Dickson DW, Duyckaerts C, Frosch MP, Masliah E, Mirra SS, Nelson PT, Schneider JA, Thal DR, Trojanowski JQ, Vinters HV, Hyman BT, National Institute on Aging, Alzheimer's Association (2012) National Institute on Aging-Alzheimer's Association guidelines for the neuropathologic assessment of Alzheimer's disease: A practical approach. Acta Neuropathol 123, 1-11.

[17] Cairns NJ, Bigio EH, Mackenzie IR, Neumann M, Lee VM, Hatanpaa KJ, White 3rd CL, Schneider JA, Grinberg LT, Halliday G, Duyckaerts C, Lowe JS, Holm IE, Tolnay M, Okamoto K, Yokoo H, Murayama S, Woulfe J, Munoz DG, Dickson DW, Ince PG, Trojanowski JQ, Mann DM, Consortium for Frontotemporal Lobar Degeneration (2007) Neuropathologic diagnostic and nosologic criteria for frontotemporal lobar degeneration: Consensus of the Consortium for Frontotemporal Lobar Degeneration. Acta Neuropathol 114, 5-22.

[18] Mackenzie IR, Neumann M, Baborie A, Sampathu DM, Du Plessis D, Jaros E, Perry RH, Trojanowski JQ, Mann DM, Lee VM (2011) A harmonized classification system for FTLD-TDP pathology. Acta Neuropathol 122, 111-113.
[19] Mackenzie IR, Neumann M, Bigio EH, Cairns NJ, Alafuzoff I, Kril J, Kovacs GG, Ghetti B, Halliday G, Holm IE, Ince PG, Kamphorst W, Revesz T, Rozemuller AJ, Kumar-Singh S, Akiyama H, Baborie A, Spina S, Dickson DW, Trojanowski JQ, Mann DM (2010) Nomenclature and nosology for neuropathologic subtypes of frontotemporal lobar degeneration: An update. Acta Neuropathol 119, 1-4.

[20] Markesbery WR (1998) Neuropathology of dementing disorders, Arnold.

[21] Van der Mussele S, Fransen E, Struyfs H, Luyckx J, Marien P, Saerens J, Somers N, Goeman J, De Deyn PP, Engelborghs S (2014) Depression in mild cognitive impairment is associated with progression to Alzheimer's disease: A longitudinal study. J Alzheimers Dis 42, 1239-1250.

[22] Shaw LM, Vanderstichele H, Knapik-Czajka M, Clark CM, Aisen PS, Petersen RC, Blennow K, Soares H, Simon A, Lewczuk P, Dean R, Siemers E, Potter W, Lee VM, Trojanowski JQ, Alzheimer's Disease Neuroimaging Initiative (2009) Cerebrospinal fluid biomarker signature in Alzheimer's disease neuroimaging initiative subjects. Ann Neurol 65, 403-413.

[23] Clark CM, Pontecorvo MJ, Beach TG, Bedell BJ, Coleman RE, Doraiswamy PM, Fleisher AS, Reiman EM, Sabbagh MN, Sadowsky CH, Schneider JA, Arora A, Carpenter AP, Flitter ML, Joshi AD, Krautkramer MJ, Lu M, Mintun MA, Skovronsky DM, AV-45-A16 Study Group (2012) Cerebral PET with florbetapir compared with neuropathology at autopsy for detection of neuritic amyloid-beta plaques: A prospective cohort study. Lancet Neurol 11, 669-678.

[24] Toledo JB, Brettschneider J, Grossman M, Arnold SE, Hu WT, Xie SX, Lee VM, Shaw LM, Trojanowski JQ (2012) CSF biomarkers cutoffs: The importance of coincident neuropathological diseases. Acta Neuropathol 124, 23-35.

[25] Rowe CC, Bourgeat P, Ellis KA, Brown B, Lim YY, Mulligan R, Jones G, Maruff P, Woodward M, Price R, Robins P, Tochon-Danguy H, O' Keefe G, Pike KE, Yates P, Szoeke C, Salvado O, Macaulay SL, O'Meara T, Head R, Cobiac L, Savage G, Martins R, Masters CL, Ames D, Villemagne VL (2013) Predicting Alzheimer disease with beta-amyloid imaging: Results from the Australian imaging, biomarkers, and lifestyle study of ageing. Ann Neurol 74, 905-913.

[26] Lattanzio F, Abu-Rumeileh S, Franceschini A, Kai H, Amore G, Poggiolini I, Rossi M, Baiardi S, McGuire L, Ladogana A, Pocchiari M, Green A, Capellari S, Parchi $P$ (2017) Prion-specific and surrogate CSF biomarkers in Creutzfeldt-Jakob disease: Diagnostic accuracy in relation to molecular subtypes and analysis of neuropathological correlates of p-tau and Abeta42 levels. Acta Neuropathol 133, 559-578.

[27] Schoonenboom NS, Reesink FE, Verwey NA, Kester MI, Teunissen CE, van de Ven PM, Pijnenburg YA, Blankenstein MA, Rozemuller AJ, Scheltens P, van der Flier WM (2012) Cerebrospinal fluid markers for differential dementia diagnosis in a large memory clinic cohort. Neurology $\mathbf{7 8}$, 47-54.

[28] Slaets S, Le Bastard N, Martin JJ, Sleegers K, Van Broeckhoven C, De Deyn PP, Engelborghs S (2013) Cerebrospinal fluid Abeta1-40 improves differential dementia diagnosis in patients with intermediate P-tau181P levels. J Alzheimers Dis 36, 759-767.

[29] Blennow K, Hampel H, Weiner M, Zetterberg H (2010) Cerebrospinal fluid and plasma biomarkers in Alzheimer disease. Nat Rev Neurol 6, 131-144.

[30] Kapaki E, Kilidireas K, Paraskevas GP, Michalopoulou M, Patsouris E (2001) Highly increased CSF tau protein and 
decreased beta-amyloid (1-42) in sporadic CJD: A discrimination from Alzheimer's disease? J Neurol Neurosurg Psychiatry 71, 401-403.

[31] Baldeiras IE, Ribeiro MH, Pacheco P, Machado A, Santana I, Cunha L, Oliveira CR (2009) Diagnostic value of CSF protein profile in a Portuguese population of SCJD patients. J Neurol 256, 1540-1550.

[32] Niemantsverdriet E, Ottoy J, Somers C, De Roeck E, Struyfs H, Soetewey F, Verhaeghe J, Van den Bosche T, Van Mossevelde S, Goeman J, De Deyn PP, Marien P, Versijpt J, Sleegers K, Van Broeckhoven C, wyffels L, Albert A, Ceyssens S, Stroobants S, Staelens S, Bjerke M, Engelborghs $S$ (2017) The cerebrospinal fluid $A \beta 1-42 / A \beta 1-40$ ratio improves concordance with amyloid-PET for diagnosing Alzheimer's disease in a clinical setting. J Alzheimers Dis 60, 561-576.

[33] Herukka SK, Simonsen AH, Andreasen N, Baldeiras I, Bjerke M, Blennow K, Engelborghs S, Frisoni GB,
Gabryelewicz T, Galluzzi S, Handels R, Kramberger MG, Kulczynska A, Molinuevo JL, Mroczko B, Nordberg A, Oliveira CR, Otto M, Rinne JO, Rot U, Saka E, Soininen H, Struyfs H, Suardi S, Visser PJ, Winblad B, Zetterberg H, Waldemar G (2017) Recommendations for cerebrospinal fluid Alzheimer's disease biomarkers in the diagnostic evaluation of mild cognitive impairment. Alzheimers Dement 13, 285-295.

[34] Simonsen AH, Herukka SK, Andreasen N, Baldeiras I, Bjerke M, Blennow K, Engelborghs S, Frisoni GB, Gabryelewicz T, Galluzzi S, Handels R, Kramberger MG, Kulczynska A, Molinuevo JL, Mroczko B, Nordberg A, Oliveira CR, Otto M, Rinne JO, Rot U, Saka E, Soininen H, Struyfs H, Suardi S, Visser PJ, Winblad B, Zetterberg H, Waldemar G (2017) Recommendations for CSF $\mathrm{AD}$ biomarkers in the diagnostic evaluation of dementia. Alzheimers Dement 13, 274-284. 